
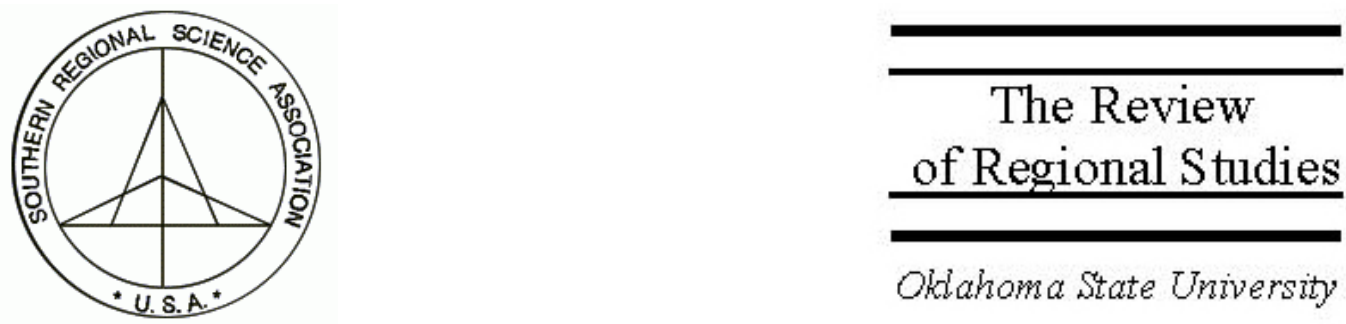

\title{
State-Local Revenue Diversification, Stability, and Growth: Time Series Evidence
}

\author{
Donald Schunk \\ Moore School of Business, University of South Carolina, Columbia, SC 29208, \\ e-mail:dschunk@moore.sc.edu \\ Sanela Porca \\ School of Business Administration, University of South Carolina Aiken, Aiken, SC \\ 29801,e-mail: sanelap@usca.edu
}

\begin{abstract}
A common argument put forth in tax reform discussions is that a balanced revenue system is better equipped to handle downturns. The purpose of this paper is to consider the empirical relationship between a scalar measure of the diversity of a state's state-local revenue system and the stability and growth of that revenue system. This evidence is drawn from panel data vector autoregression models. Impulse response analysis from these PVARs indicates that movements toward greater revenue system balance lead to greater revenue growth stability as well as faster rates of revenue growth itself.
\end{abstract}

Keywords: Government revenue diversity; Government revenue stability; Government revenue growth; Panel vector autoregressions

JEL classification: $H 7 ;$ R5; C3

The authors wish to thank Dan Rickman, Douglas Woodward, and two anonymous referees for insightful feedback. An earlier version of this paper was presented at the $97^{\text {th }}$ Annual Conference of the National Tax Association, Minneapolis, Minnesota, November 2004. 


\section{INTRODUCTION}

Over the course of every business cycle, U.S. state budgets face episodes of revenue instability. While all states (except Vermont) require balanced budgets, economic expansions and contractions continually confound revenue forecasts and cause constant changes to spending and tax policy. For example, revenue surprises during economic prosperity lead to expanded state government spending and encourage tax cuts; then as the economy slides into recession, state revenue shortfalls trigger sudden, debilitating spending cuts. Then the process starts anew: swelling revenue supports new programs during booms, while the elimination of government programs during shortfalls undermines these efforts. Across the country, the funding needed to support annual state budgets is never reliable.

Because economic cycles create a climate of ongoing revenue uncertainty, government decisions inevitably take place in a crisis-like atmosphere. This often leads to the unplanned, inefficient (i.e., across-the-board) budget cuts that typify state policy during fiscal crises. Yet when the economy expands, the need to reform the budgetary process is forgotten as revenues rise above the long-term trend. Stable and predictable revenue to run state government programs is elusive.

Since volatility ultimately plays an important role in shaping state budgets, the determinants of revenue instability should be better understood. Beyond cyclical problems, revenue volatility may be exacerbated by structural issues. In particular, a state's particular mix of taxes may engender fiscal instability if it is weighted too heavily toward volatile revenue sources. Thus, the relative shares of sales, income, and other taxes that comprise total revenue may influence revenue fluctuations across states. The tax structure - the revenue portfolio and its diversification - remains a political choice, even if cyclical instability remains unavoidable.

This paper investigates the causes of revenue variability across U.S. states, focusing on the effects of economic volatility and revenue source diversification. We assess the state's state and local portfolio of revenue (essentially, the balance between sales, income, and property taxes and non-tax revenues) as a potential stabilizing force, after controlling for economic fluctuation. Revenue diversification has received limited empirical analysis in the context of state budgetary fluctuation, although it is well-known in other areas of economics. Markowitz (1952) established the notion of diversification in the context of an investment portfolio. Moreover, empirical evaluations of diversification spread to regional economics, where the focus turned to the diversity of a region's industrial portfolio and the implications for economic stability and growth (Conroy 1975).

In the public finance literature, considerable attention has been given to the related issue of the revenue portfolio, that is, the role that specific revenue sources play in providing both revenue growth and stability. For instance, Harmon and Mallick (1994) analyzed the growth, stability, and progressivity of individual taxes in New York for 
1970-1991. Gentry and Ladd (1994) analyzed growth-stability issues with Massachusetts and North Carolina. Misiolek and Perdue (1987) studied seven main revenue producers for Georgia (1970-1981).

Precise measurement of revenue diversification in the budget portfolio, however, has not received much attention. Until the 1990s, the public finance literature treated revenue diversification in an ad hoc fashion. Revenue systems were generally viewed as balanced if the shares of major revenue sources fell in some pre-determined range. For example, applying a variant of the Hirschman-Herfindahl index to state-local revenues, Suyderhoud (1994) represents the first attempt to distill revenue systems down to a single measure of revenue diversification. While this kind of single diversity measure has been used in different settings, the role such a measure of diversity may play in explaining revenue instability has been overlooked.

This is the first study that attempts to look at the dynamic relationship between a scalar measure of diversification and revenue growth variability. This paper also considers the dynamic relationship between revenue diversity and revenue growth itself. The analysis covers the 48 contiguous U.S. states from the late 1970s to 2000. Specifically, we construct measures of state and local revenue diversification, revenue growth and variability, and economic growth and variability. Using a set of panel vector autoregressions, we then consider the dynamic impacts of changes in revenue diversification or economic conditions on revenue growth and revenue variability.

The rest of this paper is organized as follows. A review of the revenue portfolio literature is given in Section 2. Section 3 offers a description of the data constructed and econometric techniques used in this paper. The results of the panel VARs are given in Section 4 in terms of estimated impulse response functions. A summary and conclusion is offered in the final section.

\section{LITERATURE ON REVENUE PORTFOLIOS}

Observed state revenue portfolios (and potentially revenue stability) are the result of many different and often competing factors. As mentioned in the introduction, a critical issue in judging various determinants of state revenue growth variability is whether the instability is a result of structural or cyclical budget imbalances. Cyclical imbalances via economic fluctuations do not necessarily require making changes to the revenue system; rather, they are a natural feature of the business cycle. However, a structural imbalance - that part of revenue variability caused by the mix of revenue sources - generally requires making permanent changes to the revenue portfolio. This section provides an overview of the literature, highlighting the relationship between tax structures and the characteristics of the overall tax system.

White (1983) pioneered the portfolio choice model of tax structures by modifying the portfolio model of finance theory. The centerpiece of the portfolio approach is the derivation of a frontier that depicts the trade-off among characteristics of a state's tax system. 
Misiolek and Perdue (1987) redefined White's growth-instability frontier in terms of real and nominal frontiers by recognizing that factors such as inflation can affect different taxes differently. They found that the efficient frontier in nominal terms might be inefficient when a government's goal is real revenue stabilization. Their focus was on seven main revenue sources for the state of Georgia during 1970-1981. Similarly, Gentry and Ladd (1994) extended White's methodology and incorporated a broader set of characteristics and directly compared two states, Massachusetts and North Carolina. They focused on four characteristics of state structures: revenue growth, stability, equity, and competitiveness. Harmon and Mallick (1994) further extended White's portfolio approach to include equity considerations. They analyzed the growth, stability, and progressivity of individual taxes in New York State. Braun and Otsuka (1998) examined the contributions of a state's economic condition and the tax structure to the growth and variability of tax revenue flow. Their focus was on how the tax structure interacts with the state economy to constrain the choices reachable to the government officials.

In addition to this literature, other revenue portfolios studies evaluate different characteristics of the tax structure. These include four broad classes of studies: (1) tax exporting (Gade and Adkins 1990; Morgan, Mutti, and Rickman 1996), (2) tax competition (Kanbur and Keen 1993; Fuest 2000; Porca 2002), (3) elasticity of the tax system, and (4) complexity of the tax structure (Wagner 1976; Warskett, Winer, and Hettich 1998).

The public finance literature also offers an alternative to the portfolio choice model. Optimal taxation theory uses a general equilibrium approach to focus on the trade-off between equity goals and the deadweight loss of taxation. This integration of equity and efficiency goals requires policy makers to determine a tax structure such that it minimizes deadweight losses for particular distributional goals. The optimal taxation literature is in favor of taxing consumption rather than income and is in favor of inverse elasticity rule (Ramsey 1927; Diamond and Mirrlees 1971; Stiglitz and Boskin 1977; Shoven and Whalley 1992).

Generally, the tax portfolio literature is primarily focused on estimating the characteristics of individual tax sources and then simulating the effects on various tax structure characteristics by altering the mix of taxes. That is, these studies typically work backward from specific source characteristics to a tax structure frontier showing the different potential tax system outcomes in terms of such measures as growth, equity, and stability.

The approach taken in this paper diverges from previous work. Our goal is first to distill the diversity of state revenue systems into a single metric and then to consider the relationship with observed revenue growth and growth variability. An important lesson from the public finance literature, however, concerns the potential trade-offs among alternative revenue goals. As suggested earlier, we focus on revenue growth stability in part because of the perceived importance of revenue stability given the potentially inefficient expenditure decisions made in an environment of chaotic swings in revenue. We also consider the relationship between revenue balance and average revenue growth rates. 
We recognize, however, the need for further research into the relationship between measures of revenue diversity and revenue system goals beyond stability and growth.

\section{DATA AND ECONOMETRIC ISSUES}

\subsection{Variable Construction}

In the public finance literature, the degree of revenue variability over time is typically calculated as either the standard deviation of annual revenue growth rates over some interval or as the estimated elasticity of revenue growth relative to personal income growth. For our purposes, we are interested in forming an annual observation for state and local revenue growth variability within each state. One approach would be to calculate a form of moving standard deviation of revenue growth rates for each state. This would, however, be somewhat arbitrary given the necessary choice of length for the sliding span of growth rates.

An alternative is to turn to a time series model that is explicitly designed to model the volatility in a time series. As such, we use a series of state-level GARCH models to first model each state's state-local revenue growth volatility and then to generate annual observations on each state's conditional standard deviation of revenue growth. Specifically, the GARCH(1,1) models are of the form:

$$
\begin{gathered}
\text { REVGROWTH } H_{t}=c+\varepsilon_{t} \\
\varepsilon_{t} \mid \Omega_{t-1} \sim N\left(0, \sigma_{t}^{2}\right) \\
\sigma_{t}^{2}=\omega+\alpha \varepsilon_{t-1}^{2}+\beta \sigma_{t-1}^{2}
\end{gathered}
$$

where REVGROWTH for each state is the annual growth rate of total state and local general revenue from own sources from the U.S. Census Bureau's State and Local Government Finance database for 1978 through 2000. The annual observations for each state's revenue variability (REVVAR) are then the one-step-ahead forecasts of the conditional standard deviation. That is, for each state $R E V V A R_{t}=\sigma_{t}$ as calculated at date $t-1$.

Fluctuations in revenue growth are likely affected by fluctuations in personal income growth because personal income is a key driver for revenue collections. The measure of personal income growth variability (INCVAR) used here is also generated from a series of GARCH models used to model the conditional variance of annual state personal income

\footnotetext{
${ }^{1}$ The GARCH models were checked to ensure the usual properties of nonnegative and covariancestationary variances. In addition, as an alternative to using GARCH models, the simple five-year moving standard deviation of growth rates was also calculated for each state. All conclusions that follow are robust across both of these measures of revenue variability. This also applies to the construction of the personal income variability measure discussed below.
} 
growth (INCGROWTH). Quarterly state personal income data from the U.S. Bureau of Economic Analysis were converted to a fiscal year basis for this analysis.

Previous attempts to analyze the role of revenue diversification have utilized a form of Hirschman-Herfindahl Index as has long been used to measure industry concentration in industrial organization. Among the first to apply this measure to revenue diversification was Suyderhoud (1994), who looked at revenue diversification among state and local governments. In the current paper, the Hirschman-Herfindahl Diversification Index $(H H I)$ for state $n$ at date $t$ is calculated as:

$$
H H I_{n, t}=\frac{1-\sum_{i=1}^{5} X_{i, n, t}{ }^{2}}{0.857}
$$

where $X_{i, n, t}$ is the share of total revenue from source $i$ for state $n$ at date $t$. We calculate this index for every state and every year using seven sources of state and local general revenue: property taxes, general sales taxes, selective sales taxes, individual income taxes, corporate income taxes, total charges and miscellaneous general revenue, and all other taxes. If all of the seven revenue source shares are identical at 0.1429 , then the numerator will be 0.857 and the index will equal 1 . At the other extreme, if revenue is derived from just one source, that source's fraction equals 1 , the numerator equals 0 , and the index equals 0 . This is not to suggest that perfectly equal revenue shares between these seven sources constitute an optimal portfolio. Rather, this index serves as a useful metric for cross-state and dynamic comparisons of relative revenue diversity.

Figure 1 shows the cross-state average for $H H I$ from fiscal year 1977 through 2000. The average trend over this period has been for less balance in state and local revenue systems. However, this state average obviously masks a great deal of variation across states. For example, the HHI for South Carolina in Figure 2 has shown a relatively steady decline due to a fairly gradual shift in relative importance from general and selective sales taxes and corporate income taxes towards charges and fees. In Figure 3, New Mexico saw a decline in revenue balance through the mid-1980s as the state's reliance on charges and fees rose from about 34 percent of general revenue in 1977 to nearly 54 percent by fiscal year 1984. From 1984 on, New Mexico's system has generally been moving toward more balance as the percentage of revenue from charges and fees has fallen and the shares of general sales and individual income taxes have risen.

In addition to the dynamic relationship between revenue diversity and revenue and economic variability, we also consider the relationship to revenue growth itself. For this purpose, we use annual revenue growth (REVGROWTH) and personal income growth (INCGROWTH) rates. Table 1 provides the means of each variable for each state across the full time period 1978-2000. However, the purpose here is to investigate the dynamic relationships between these variables rather than just these cross-sectional patterns in Table 1. By exploiting the dynamics between these variables, it will be possible to 
estimate the potential effects of changes in revenue diversification on revenue growth and variability. Cross-sectional or standard panel data analyses cannot provide this type of information; they can only indicate the nature of correlation without directly suggesting what a state may experience if it sees a change in its degree of revenue balance.

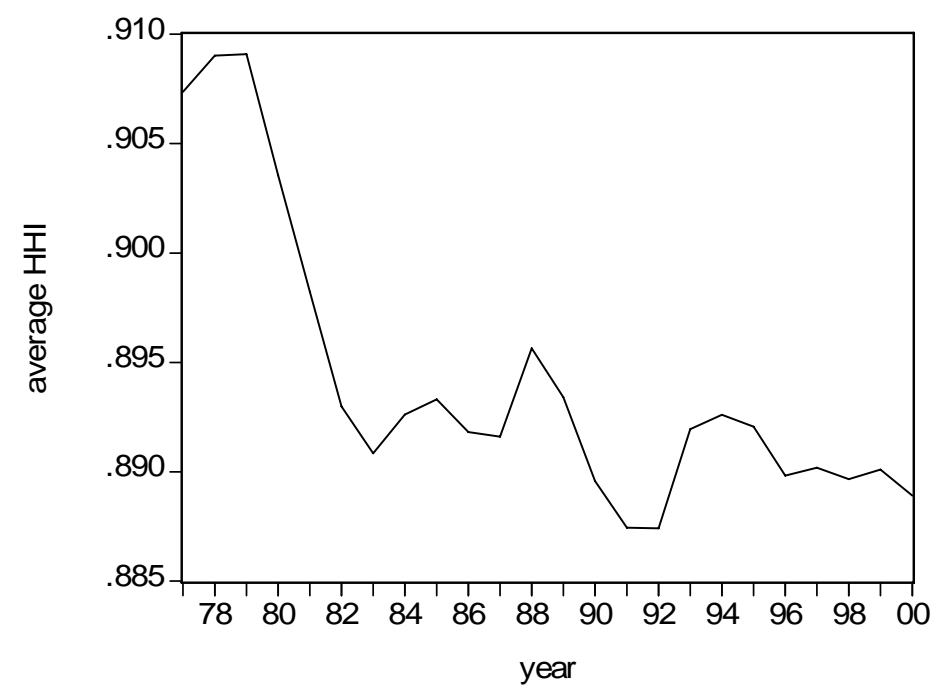

FIGURE 1. Average HHI across States

Note: This is the unweighted mean of the HHI for the 48 states.

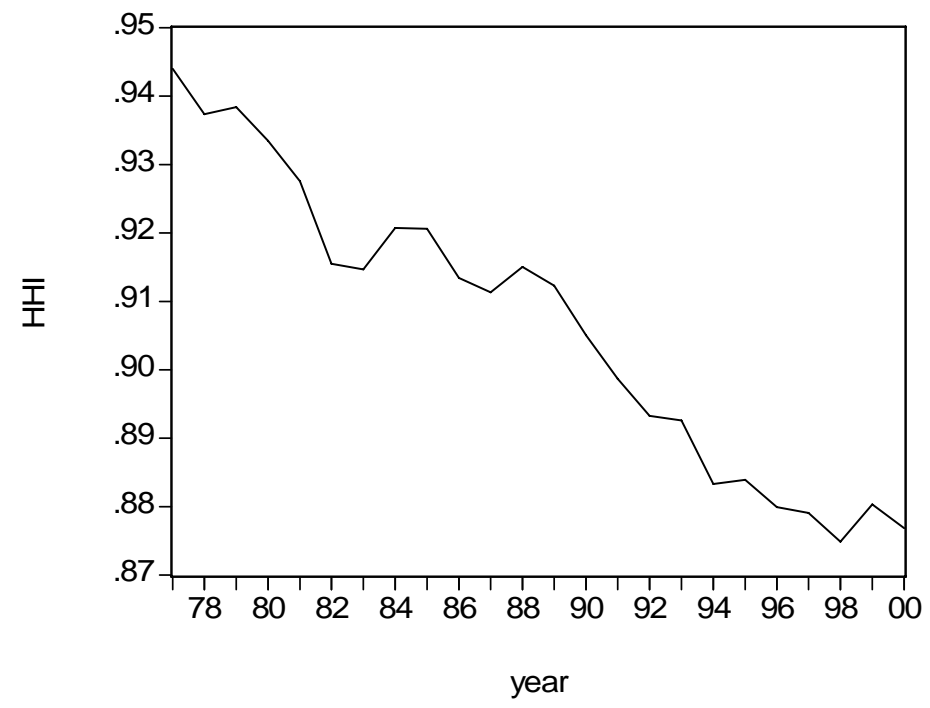

FIGURE 2. South Carolina's HHI, 1977-2000 


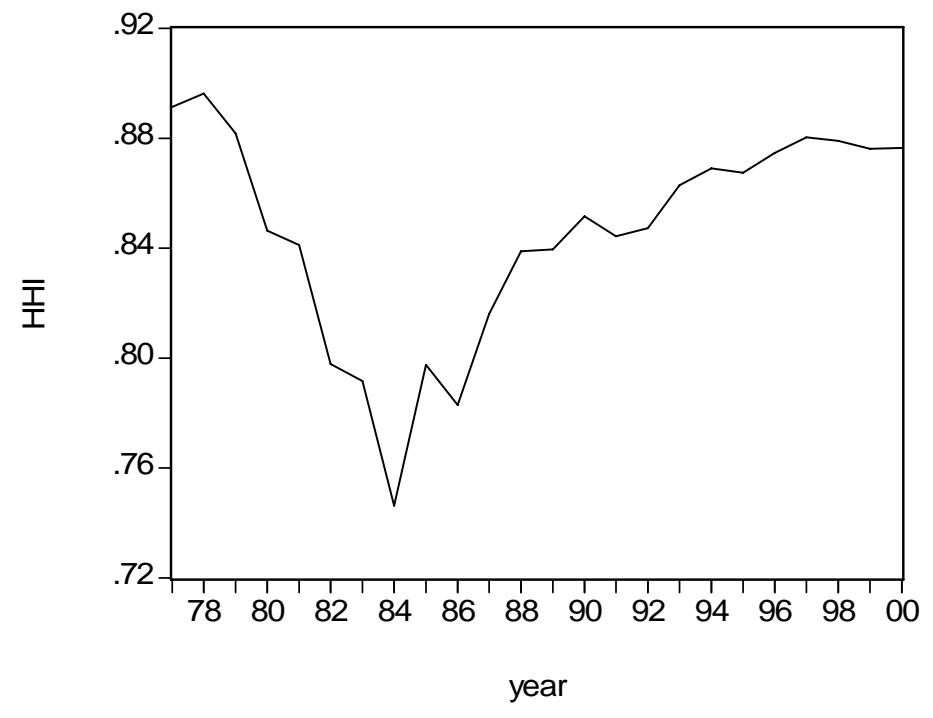

FIGURE 3. New Mexico’s HHI, 1977-2000

\subsection{Panel VARs}

The first examples of PVARs were offered by Holtz-Eakin, Newey, and Rosen $(1988,1989)$. A three variable PVAR of state and local revenue growth variability (REVVAR), personal income growth variability (INCVAR), and the HHI index of revenue diversification consists of the following three single equations:

$$
\begin{aligned}
& \operatorname{REVVAR}_{i, t}=\sum_{l=1}^{p} \alpha_{11 R E V V A R}, t-l+\sum_{l=1}^{p} \beta_{11 I N C V A R}, t-l+\sum_{l=1}^{p} \delta 11 H H I_{i, t-l}+\eta_{1, i}+\varepsilon 1 i, t \\
& \operatorname{INCVAR}_{i, t}=\sum_{l=1}^{p} \alpha_{2 l} R_{\text {EVVAR }}, t-l+\sum_{l=1}^{p} \beta_{2 l} I N C V A R_{i, t}-l+\sum_{l=1}^{p} \delta_{2 l} H H I_{i, t}-l+\eta_{2, i}+\varepsilon_{2 i, t} \\
& H H I_{i, t}=\sum_{l=1}^{p} \alpha_{3 l} R_{E V V A R}, t-l+\sum_{l=1}^{p} \beta_{3 l} I N C V A R i, t-l+\sum_{l=1}^{p} \delta_{3 l} H_{H} I_{i, t}-l+\eta_{3, i}+\varepsilon 3 i, t
\end{aligned}
$$

where $\eta_{1, i}, \eta_{2, i}$, and $\eta_{3, i}$ are unobserved state fixed effects and the errors in each equation are assumed to be individually white noise but may be contemporaneously correlated across equations. The standard VAR coefficients are restricted to be identical across all states, that is, we are assuming the dynamic relationships between REVVAR, INCVAR and $H H I$ are identical across states while allowing for state heterogeneity to enter through the unobservable fixed effects. Replacing REVVAR and INCVAR with REVGROWTH and INCGROWTH in equations 1 through 3 provides a PVAR to estimate the dynamic relationship between revenue growth, income growth, and revenue diversification. 
TABLE 1

Full-Sample Means of Variables by State

\begin{tabular}{lccccc}
\hline State & HHI & REVVAR & INCVAR & REVGROWTH & PIGROWTH \\
\hline Alabama & 0.900 & 3.9 & 2.0 & 8.0 & 7.3 \\
Arizona & 0.919 & 4.0 & 3.1 & 9.3 & 9.8 \\
Arkansas & 0.936 & 3.6 & 1.9 & 8.3 & 7.2 \\
California & 0.938 & 4.0 & 2.9 & 8.1 & 8.0 \\
Colorado & 0.909 & 4.0 & 3.2 & 8.8 & 9.0 \\
Connecticut & 0.925 & 4.4 & 3.0 & 8.2 & 7.6 \\
Delaware & 0.886 & 4.3 & 2.1 & 8.7 & 7.4 \\
Florida & 0.894 & 3.8 & 3.6 & 10.0 & 9.3 \\
Georgia & 0.922 & 2.6 & 2.0 & 9.3 & 9.0 \\
Idaho & 0.932 & 3.2 & 2.3 & 8.9 & 7.8 \\
Illinois & 0.941 & 2.2 & 1.5 & 6.9 & 6.5 \\
Indiana & 0.914 & 3.6 & 1.5 & 7.8 & 6.7 \\
Iowa & 0.922 & 2.0 & 1.9 & 6.6 & 6.0 \\
Kansas & 0.923 & 3.7 & 2.4 & 7.2 & 6.8 \\
Kentucky & 0.950 & 3.7 & 1.9 & 7.7 & 7.0 \\
Louisiana & 0.896 & 4.8 & 3.8 & 7.4 & 6.7 \\
Maine & 0.931 & 3.9 & 3.0 & 8.6 & 7.2 \\
Maryland & 0.931 & 2.8 & 2.6 & 7.5 & 7.6 \\
Massachusetts & 0.920 & 2.4 & 2.8 & 7.0 & 7.7 \\
Michigan & 0.926 & 2.4 & 1.9 & 6.8 & 6.5 \\
Minnesota & 0.930 & 3.7 & 2.3 & 7.8 & 7.6 \\
Mississippi & 0.902 & 3.1 & 1.9 & 7.8 & 7.1 \\
Missouri & 0.940 & 2.9 & 2.0 & 7.7 & 6.9 \\
Montana & 0.880 & 6.3 & 2.2 & 7.1 & 6.4 \\
Nebraska & 0.908 & 2.7 & 2.3 & 6.7 & 6.8 \\
Nevada & 0.899 & 3.4 & 2.3 & 11.1 & 11.0 \\
New Hampshire & 0.803 & 4.6 & 4.0 & 8.9 & 8.9 \\
New Jersey & 0.915 & 3.5 & 2.5 & 7.6 & 7.5 \\
New Mexico & 0.861 & 8.6 & 3.0 & 9.0 & 7.8 \\
New York & 0.942 & 3.0 & 2.5 & 6.5 & 6.9 \\
North Carolina & 0.947 & 2.7 & 1.9 & 9.3 & 8.5 \\
North Dakota & 0.897 & 4.7 & 4.4 & 6.5 & 6.4 \\
Ohio & 0.936 & 2.7 & 1.7 & 7.6 & 6.4 \\
Oklahoma & 0.937 & 6.8 & 4.0 & 7.9 & 7.0 \\
Oregon & 0.870 & 2.9 & 1.8 & 8.2 & 7.6 \\
Pennsylvania & 0.962 & 3.6 & 2.2 & 7.1 & 6.4 \\
Rhode Island & 0.920 & 3.4 & 2.7 & 7.3 & 7.0 \\
South Carolina & 0.924 & 2.4 & 2.2 & 9.1 & 8.1 \\
South Dakota & 0.876 & 4.9 & 2.4 & 6.8 & 7.1 \\
Tennessee & 0.891 & 2.8 & 1.9 & 7.9 & 7.9 \\
Texas & 0.895 & 4.0 & 3.5 & 8.9 & 8.6 \\
Utah & 0.909 & 4.9 & 2.6 & 9.7 & 8.6 \\
Vermont & 0.920 & 3.6 & 2.9 & 7.7 & 7.9 \\
Virginia & 0.942 & 2.8 & 3.0 & 8.8 & 8.2 \\
Washington & 0.869 & 3.0 & 2.6 & 8.7 & 8.6 \\
West Virginia & 0.940 & 4.1 & 2.1 & 6.9 & 5.7 \\
Wisconsin & 0.932 & 1.8 & 1.5 & 7.3 & 6.9 \\
Wyoming & 0.832 & 11.0 & 3.9 & 7.6 & 6.9 \\
\hline & & & & & \\
\hline
\end{tabular}


In addition to Holtz-Eakin, Newey, and Rosen (1988, 1989), Choe (2003) used a PVAR to estimate the relationships between economic growth, foreign direct investment, and gross domestic investment for a sample of 80 countries. Rousseau and Wachtel (2000) considered the relationships between per capita output, the intensity of financial intermediation, and measures of equity market activity for 47 countries. Kangasharju and Moisio (1997) looked at firm births and deaths for 88 subregions of Finland. Each of these studies approaches estimating a PVAR by estimating the single equations individually, as initially suggested by Holtz-Eakin, Newey, and Rosen. As such, the estimation of a PVAR has been treated identically to the estimation of a series of dynamic panel data models.

There is a well-known problem when trying to estimate a single equation dynamic panel data model with unobserved heterogeneity. For example, consider the estimation of equation (1) of the PVAR given above. In a static panel case, one approach is to simply include a set of state dummy variables to allow for an intercept shift. The resulting least squares dummy variable (LSDV) or within estimator will be biased in this case when lags of the dependent variable appear on the right-hand side. This is due to the fact that the LSDV estimator is equivalent to a regression involving demeaned variables. As such, the demeaned error term will be correlated with the lagged dependent variable regressors.

The literature has produced several alternatives to the LSDV or within estimator for the case of dynamic panel data models with fixed effects. A common approach is to first remove the individual fixed effects by taking take the first differences of equation (1) and estimate the following:

$$
\begin{aligned}
& \left(\operatorname{REVVAR}_{i, t}-\operatorname{REVVAR}_{i, t}-1\right)=\sum_{l=1}^{p} \alpha_{11}\left(\operatorname{REVVAR}_{i, t-l}-\operatorname{REVVAR}_{i, t-l-1}\right) \\
& +\sum_{l=1}^{p} \beta_{1 l}\left(\operatorname{INCVAR}_{i, t-l-1}-\operatorname{INCVAR}_{i, t-l-1}\right) \\
& +\sum_{l=1}^{p} \delta 1 l\left(H H I_{i, t-l}-H H I_{i, t-l-1}\right)+(\varepsilon 1 i, t-\varepsilon 1 i, t-1)
\end{aligned}
$$

The fixed effects have been eliminated, but the presence of the lagged dependent variable still poses a problem for standard estimation. Specifically, the transformed error term is correlated with the lagged difference of the dependent variable. While least squares remains biased, this equation in differences lends itself to instrumental variables techniques.

Anderson and Hsiao (1981) proposed using the second lag of the dependent variable as an instrument for the lagged difference. Arellano and Bond (1991) proposed a generalized method of moments (GMM) approach that exploits additional orthogonality conditions by using all available lags of the dependent variable up through the second lag as 
instruments for the equation in first differences. This GMM estimation strategy for dynamic panel models has been the focus of much ongoing research. ${ }^{2}$

At the heart of this estimation approach is the use of lags of system variables as instruments for estimating equations such as (4) above. As such, estimation of any individual equation of the PVAR involves treating that equation as a system of crosssection regressions that each have a different set of valid instruments as well as crossequation coefficient restrictions to force the autoregressive parameters to be constant across time. ${ }^{3}$

For the PVAR given in equations 1, 2, and 3, unrestricted GMM estimation involves using all available lags of REVVAR, INCVAR, and HHI up to period $t$ - 2 for estimating the equations in first differences. This construct involves a large number of orthogonality conditions and a large number of overidentifying restrictions. Judson and Owen (1999) provide support for using a restricted GMM estimator that utilizes only a subset of available lags as instruments. This restricted estimator is especially useful for relatively large $T$ because the full GMM estimator quickly produces a very large number of instruments. Here we estimate the three-variable PVAR using the restricted one-step GMM estimator that uses lags 2 through 5 of each system variable as instruments for the equations in differences. Each equation is estimated using a lag length of two, and each equation also includes time fixed effects in addition to the individual fixed effects.

Given the GMM estimates of the PVAR parameters and their standard errors, we can turn to the traditional tools of time series analysis to examine the estimated dynamics of the system. In this paper, the focus will be on using impulse response functions (IRFs) to understand the dynamic relationship between REVVAR, INCVAR, and HHI and between REVGROWTH, INCGROWTH, and HHI. As in standard time series analysis, IRFs are a function of all estimated coefficients and can be used to trace the dynamic impact on all system variables following a shock to any one variable. To avoid some of the pitfalls of using either a Cholesky decomposition or a structural VAR, we construct generalized IRFs (GIRFs) as in Pesaran and Shin (1998).

GIRFs do not require specific structural restrictions and are invariant to the ordering of variables in the VAR. This stands in contrast to a Cholesky decomposition where the IRFs depend on the specific ordering of the variables. A GIRF is found by taking the difference of two conditional expectations of the vector of variables included in the VAR. More specifically, following directly from Pesaran and Shin (1998), the GIRF is given by:

$$
G I_{x}\left(n, \delta_{j}, \boldsymbol{\Omega}_{t-1}\right)=E\left(\mathbf{x}_{t+n} \mid \varepsilon_{j t}=\delta_{j}, \boldsymbol{\Omega}_{t-1}\right)-E\left(\mathbf{x}_{t+n} \mid \mathbf{\Omega}_{t-1}\right)
$$

\footnotetext{
${ }^{2}$ Arellano (2003) provides a rigorous treatment of dynamic panel data models.

3 This restriction can certainly be relaxed to allow for time-varying parameters. However, the interest in this study is to examine the dynamic relationships using traditional time-series techniques based on constant parameters.
} 
where $\mathbf{x}_{\mathrm{t}}$ is an $(m \times 1)$ vector of the $m$ variables in the VAR at date $t, \varepsilon_{j t}$ is the date $t$ error in the $j$ th equation of the VAR, $\delta_{j}$ is the shock to the $j$ th equation of the VAR, $\Omega_{t-1}$ is the information set at date $t-1$, and $n$ is the IRF horizon. Setting $\delta_{j}$ equal to the standard deviation of the VAR residual in the $j$ th equation $\left(\sigma_{j j}\right)$, it can be shown that the vector of generalized impulse responses at horizon $n$ to a shock in the $j$ th equation is given by:

$$
\Psi_{j}(n)=\sigma_{j j}{ }^{-1 / 2} \mathbf{A} n \boldsymbol{\Sigma} \mathbf{e}_{j}
$$

where $\mathbf{A} n$ is the coefficient matrix of the moving average representation of the VAR at lag $n, \Sigma$ is the covariance matrix of the VAR residuals, and $\mathbf{e}_{j}$ is an $(m \times 1)$ selection vector with one as the $j$ th element and zeros elsewhere.

The set of GIRFs are invariant to variable ordering and coincide with Cholesky orthogonalized IRFs only for shocks to the first equation of the VAR. Therefore, the GIRF for a shock to the $j$ th variable in a VAR is identical to the orthogonalized IRF where the $j$ th variable is entered first in the VAR. GIRFs have typically been used in the macroeconomics and financial literature, including Ewing and Wang (2005), Wang and Dunne (2003), and Villanueva (2005).

For the current application, a reasonable structural ordering would likely see $H H I$ first, followed by INCVAR or INCGROWTH and finally either REVVAR or REVGROWTH entered last. This ordering would imply that the degree of revenue diversification is contemporaneously exogenous with regard to both personal income and revenue movements, and that personal income can be contemporaneously affected by shocks to HHI, but not by shocks to revenues. Finally, this scheme would imply that revenue variability or growth is contemporaneously affected by shocks to both the degree of revenue diversification and personal income. With this Cholesky ordering in mind, the GIRFs following a shock to $H H I$ will be identical to the orthogonalized IRF of a shock to $H H I$. As such, any conclusions drawn from analyzing the impact of shocks to $H H I$ from the GIRFS would be the same if we instead used a Cholesky decomposition with HHI entered first, which would likely be the logical choice.

\section{ESTIMATED DYNAMICS}

Each equation of each PVAR contains six estimated coefficients excluding the fixed effects. With three equations in each PVAR and two PVARs (one for the variability measures and one for the growth rate measures), there are far too many individual parameter estimates to provide any immediately useful information. Therefore, as is common with standard VARs in time series analysis, we will immediately turn to the estimated GIRFs to understand the dynamic relationships being estimated by these PVARs. ${ }^{4}$

\footnotetext{
${ }^{4}$ The detailed PVAR estimation results are available from the author. Briefly, lags of both $H H I$ and INCVAR are significant in the REVVAR equation, as are lags of HHI and INCGROWTH in the REVGROWTH equation. In the INCGROWTH and INCVAR equations, lags of HHI are generally significant while lags of REVGROWTH or REVVAR are not. Finally, in the HHI equation from either PVAR, typically only lags of $H H I$ itself are significant.
} 
The GIRFs trace the dynamic response of all variables in the PVAR following a shock to any one variable. For example, we can trace the dynamic impact on revenue variability of an unpredictable movement in the degree of revenue diversification. The shocks that drive the GIRFs are a function of the PVAR errors, and as such generally represent movements in a system variable that could not have been predicted from within the PVAR itself.

The kinds of shocks to $H H I$ would be those that could not be linearly predicted based on the history of revenue, personal income, or HHI itself. A source of this kind of shock to revenue diversity would likely be legislative changes to the state and local revenue system that alter the overall balance of the revenue portfolio.

Figure 4 shows the dynamic response of revenue growth variability over a period of 10 years following a one standard deviation shock to HHI. This GIRF represents the impact on the conditional standard deviation of revenue growth relative to what it would have been absent the shock to the degree of revenue diversity. In this model, the one standard deviation shock amounts to a 0.01 point upward movement in the state's HHI. ${ }^{5}$

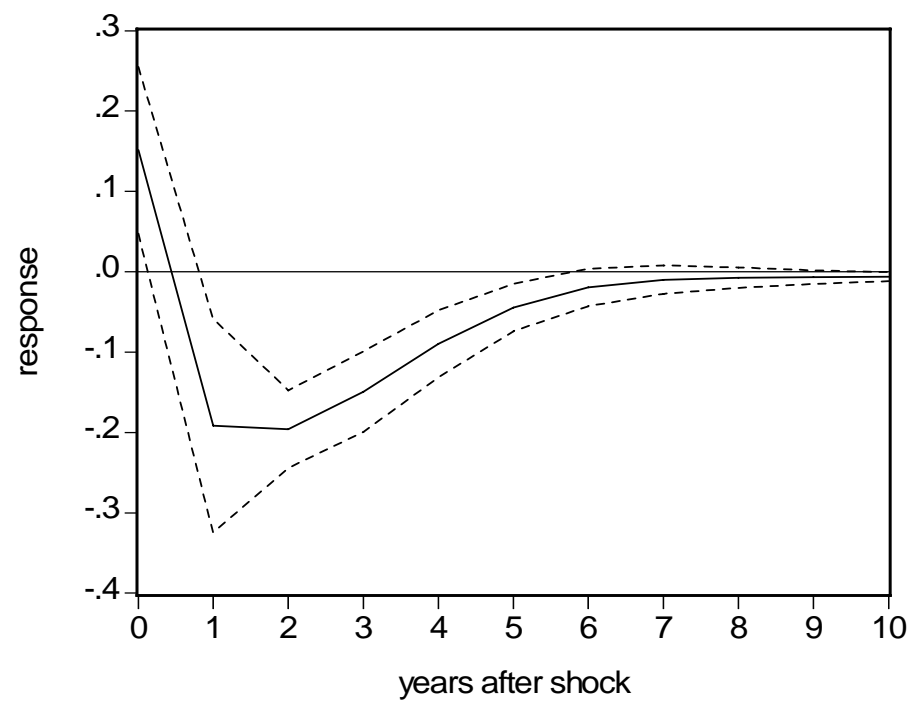

FIGURE 4. Response of REVVAR to HHI Shock

Note: The GIRF showing the response of REVVAR following a one standard deviation positive shock to HHI. Dashed lines provide the $90 \%$ Monte Carlo confidence interval based on 10,000 replications.

${ }^{5}$ As discussed previously, this response and the responses of REVVAR are identical to that obtained using a Cholesky decomposition with $\mathrm{HHI}$ as the first variable. 
The upward shock to $H H I$ has a contemporaneous upward impact on revenue growth variability of 0.15 percentage points. ${ }^{6}$ That is, the estimated PVAR indicates that an unpredictable increase in the diversity of the state and local revenue base appears to have some immediate destabilizing impact on revenue growth. An adjustment to the state and local revenue system's balance may or may not be done in a revenue neutral way. The evidence here seems to suggest that on average across states, a movement towards increased revenue balance typically involves a change in overall revenue collections that affects the current year's revenue growth rate and therefore increases the current conditional standard deviation of revenue growth.

Looking beyond the contemporaneous impact, however, the HHI shock has a downward and significant impact on revenue growth variability for the five years subsequent to the HHI shock. For years six and beyond, the response remains negative though statistically insignificant. These results do indicate that a movement towards increased revenue source balance leads to a reduction in the variability of total state and local revenue growth.

These results are especially useful considering that the measure of revenue diversification is a scalar measure independent of the precise makeup of the revenue system. That is, an upward movement in HHI occurs whenever the revenue system becomes more equally balanced, regardless of the specific revenue sources that are being affected. The relative stability of revenue sources can differ during particular time periods, but this evidence implies that on average across states and over time, a shift towards greater revenue system balance results in a more stable revenue system. These results work to support the view that promoting revenue diversity in general is one way to achieve improved revenue stability.

Figure 5 shows the response of revenue variability following an upward shock to personal income growth variability. ${ }^{7}$ Here, a period of unpredictably high income growth variability results in increased revenue variability. This positive impact is statistically significant for four years following the initial shock.

As an example of these dynamics, consider the case of New Jersey. Figure 6 shows New Jersey's HHI, INCGROWTH, and REVGROWTH. New Jersey's HHI dropped from 0.923 in 1989 to 0.911 in 1990 due to increased reliance on both property taxes and charges and fees. The revenue system has remained relatively less diversified since that period. Meanwhile, between the 1980s and 1990s, the variability of personal income in New Jersey declined. For example, the standard deviation of annual personal income

\footnotetext{
${ }^{6}$ While the HHI shocks considered here are uncorrelated with other system shocks, they are allowed to have contemporaneous impacts on all of the system variables through the contemporaneous correlation between the error terms in the PVAR equations 1, 2, and 3.

${ }^{7}$ This impact is identical to that obtained using a Cholesky decomposition where INCVAR is entered first. However, the orthogonalized IRF to a shock to INCVAR using the ordering HHI, INCVAR, REVVAR is very similar to the GIRF given here.
} 


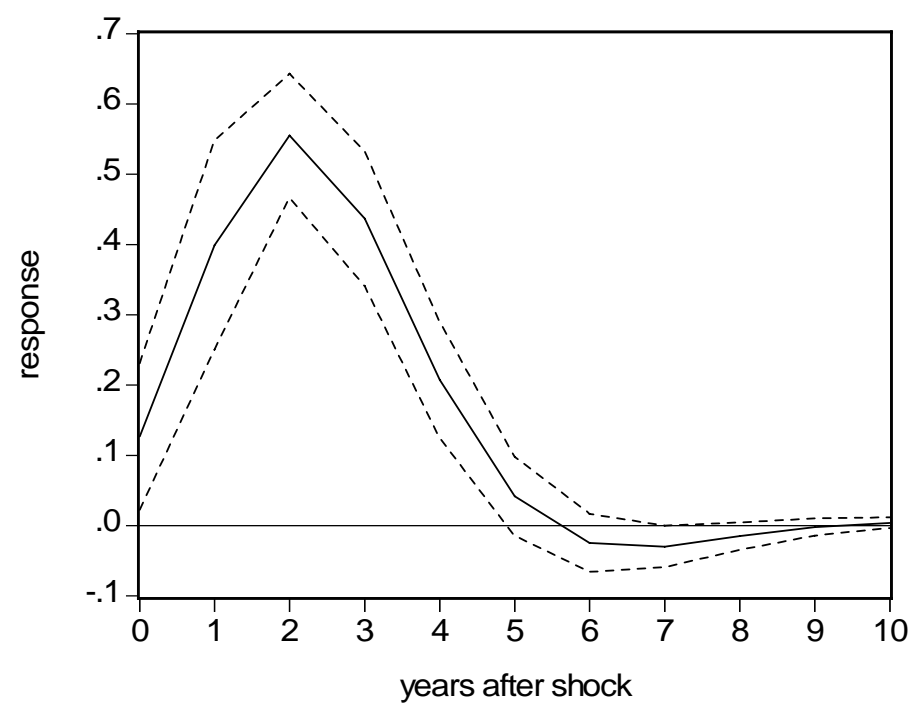

FIGURE 5. Response of REVVAR to INCVAR Shock

Note: The GIRF showing the response of REVVAR following a one standard deviation positive shock to INCVAR. Dashed lines provide the $90 \%$ Monte Carlo confidence interval based on 10,000 replications.

growth from 1978 to 1989 was 1.9. Between 1990 and 2000, the standard deviation of income growth fell to 1.3. Yet, the variability of revenue growth appears to have increased. The standard deviation of annual revenue growth between 1978 and 1989 was 2.5 but increased to 3.4 between 1990 and 2000. That is, even with more stable personal income growth, total revenue growth became more unstable during the period following the drop in revenue diversification.

However, stability is not the only goal of a revenue system. Another important consideration is the adequacy of the system. As such, while promoting revenue diversity appears to be consistent with improved stability, what are the potential impacts on revenue growth itself? Figure 7 shows the response of revenue growth to a shock to HHI. Here again, the one standard deviation shock to $H H I$ amounts to an increase of 0.01 points. The contemporaneous effect on revenue growth is -0.9 percentage points. The estimated PVAR indicates that a movement towards increased revenue balance has an immediate negative impact on overall revenue growth. This result, combined with that given earlier from Figure 4, suggests that increases in revenue diversification have historically been associated with downward pressure on revenue growth such that increases in revenue diversity may be the byproduct of cutting particular revenue sources. 


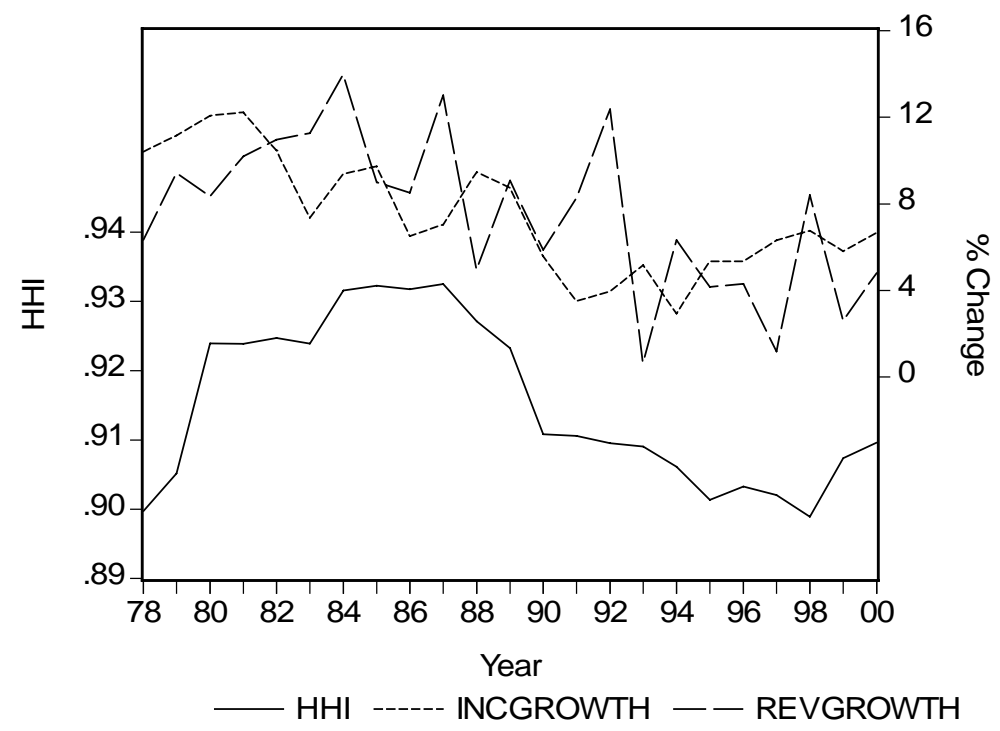

FIGURE 6. HHI, INCGROWTH, REVGROWTH for New Jersey

Note: $H H I$ is plotted against the left axis, INCGROWTH and REVGROWTH are plotted on the right axis

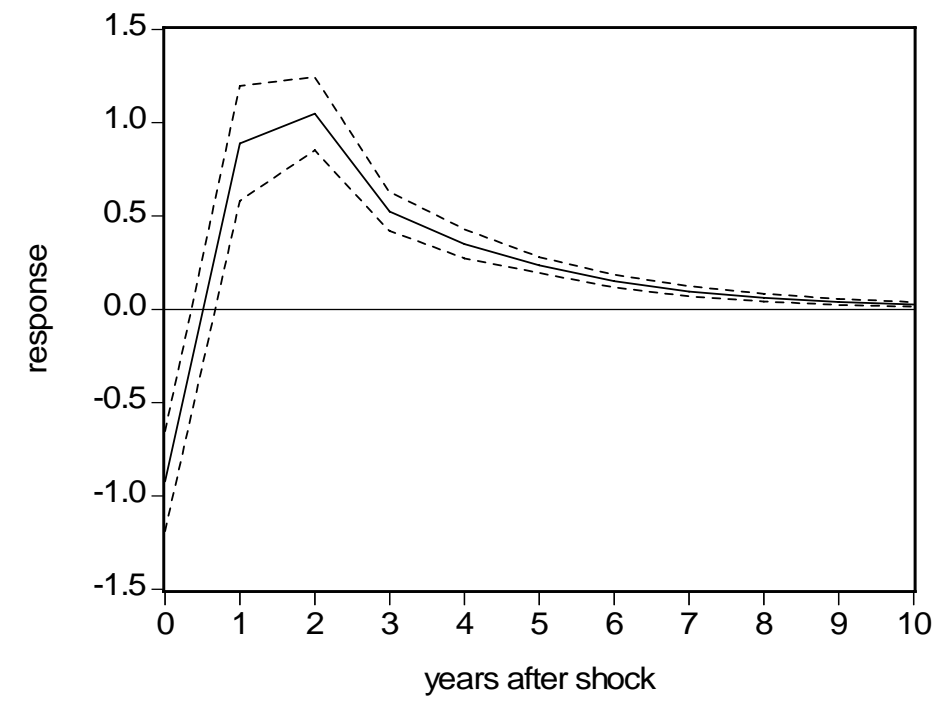

FIGURE 7. Response of REVGROWTH to HHI Shock

Note: The GIRF showing the response of REVGROWTH following a one standard deviation positive shock to HHI. Dashed lines provide the $90 \%$ Monte Carlo confidence interval based on 10,000 replications. 


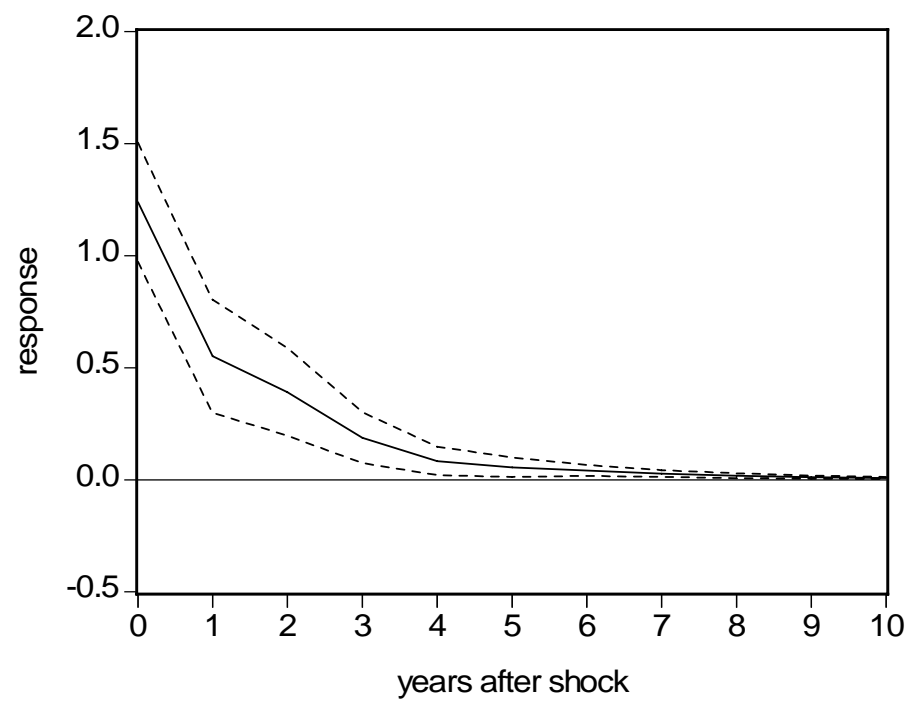

FIGURE 8. Response of REVGROWTH to INCGROWTH Shock

Note: The GIRF showing the response of REVGROWTH following a one standard deviation positive shock to INCGROWTH. Dashed lines provide the $90 \%$ Monte Carlo confidence interval based on 10,000 replications.

Over time, revenue growth is expected to be significantly greater than the baseline throughout the horizon considered here. These results suggest that a movement towards increased balance in the state and local revenue system has a positive impact on a state's revenue growth. Again, this is independent of the exact revenue sources responsible for this movement, because $H H I$ is simply a scalar measure of overall revenue balance.

Figure 8 shows the response of revenue growth following an upward shock to personal income growth. The income shock here represents an unpredictable increase in personal income growth of 2.1 percentage points. This has a contemporaneous impact of boosting revenue growth by 1.2 percentage points. As would be expected, higher income growth leads to higher revenue growth. This impact remains positive and statistically significant throughout the horizon.

\section{CONCLUSION}

This paper has considered the dynamic relationship between state and local revenue diversification and revenue variability and growth. Overall, these results indicate that movements toward increased revenue balance tend to result in both decreased revenue variability and increased revenue growth. These are the kinds of impacts that are often given in policy discussions. However, this is the first attempt in the literature to draw empirical evidence on the issue using a method explicitly designed to exploit the dynamic relationships between these variables. 
Given the importance of both personal income stability and revenue diversification in determining revenue stability, several conclusions can be drawn from the analysis. First, if revenue growth stability is a goal for state policymakers, then these results clearly suggest that achieving and maintaining a diverse revenue base is important. While policies to control the variability of personal income growth are elusive, policymakers have more or less direct control over the degree of revenue diversification. Importantly, these results indicate that this greater revenue stability can be consistent with higher revenue growth also.

However, there is another layer to this consideration, specifically, should revenue stability be a goal of policymakers? The traditional goals of tax policy include aims such as equity and neutrality. These goals are often placed in the context of the treatment of different groups of taxpayers. Yet, from the perspective of the provision of government services, large swings in revenue can lead to abrupt and unpredictable changes in government service provision.

Further, the changes in government spending that follow changes in revenue may not always represent the most efficient outcome. Decisions about starting new government programs or closing or scaling back existing programs are likely to be made more effectively in the context of a stable revenue environment rather than one that is subject to large fluctuations.

\section{REFERENCES}

Anderson, T.W. and C. Hsiao, 1981. "Estimation of Dynamic Models with Error Components," Journal of the American Statistical Association 76, 598-606.

Arellano, M., 2003. Panel Data Econometrics. Oxford University Press Inc.: New York.

Arellano, M. and S. Bond, 1991. "Some Tests of Specification for Panel Data: Monte Carlo Evidence and an Application to Employment Equations," Review of Economic Studies 58, 277-297.

Braun, B.M. and Y. Otsuka, 1998. "The Effects of Economic Conditions and Tax Structures on State Tax Revenue Flow," International Advances in Economic Research 4(3), 259-269.

Choe, J.I., 2003. "Do Foreign Direct Investment and Gross Domestic Investment Promote Economic Growth?" Review of Development Economics 7, 44-57.

Conroy, M., 1975. Regional Economic Diversification. Praeger: New York.

Diamond, P.A. and J.A. Mirrlees, 1971. "Optimal Taxation and Public Production I-II," American Economic Review 61, 8-27, 261-278.

Dye, T.R., 1992. Understanding Public Policy. Prentice Hall: Englewood Cliffs, NJ.

Ewing, B.T. and Y. Wang, 2005. "Single Housing Starts and Macroeconomic Activity: An Application of Generalized Impulse Response Analysis," Applied Economics Letters 12(3), 187-190.

Fuest, C., 2000. "The Political Economy of Tax Coordination as a Bargaining Game Between Bureaucrats and Politicians," Public Choice 103, 357-382. 
Gade, M.N. and L.C. Adkins, 1990. "Tax Exporting and State Revenue Structures," National Tax Journal 43(1), 39-52.

Gentry W.M. and H.F. Ladd, 1994. "State Tax Structure and Multiple Policy Objectives," National Tax Journal 47(4), 747-772.

Harmon, O.R. and R. Mallick, 1994. "The Optimal State Tax Portfolio Model: An Extension," National Tax Journal 42(2), 395-401.

Holtz-Eakin, D., W. Newey, and H.S. Rosen, 1988. "Estimating Vector Autoregressions with Panel Data," Econometrica 56, 1371-1395. , 1989. "The Revenues-Expenditures Nexus: Evidence from Local Government Data," International Economic Review 30, 415-429.

Judson, R.A. and A.L. Owen, 1999. "Estimating Dynamic Panel Data Models: A Guide for Macroeconomists," Economics Letters 65, 9-15.

Kanbur, S.M.R. and M. Keen, 1993. "Jeux Sans Frontiers: Tax Competition and Tax Coordination When Countries Differ in Size," American Economic Review 83, 877 893.

Kangasharju, A. and A. Moisio, 1998. "Births-Deaths Nexus of Firms: Estimating VAR with Panel Data," Small Business Economics 11, 303-313.

Markowitz, H., 1952. "Portfolio Selection," The Journal of Finance 7(1), 77-91.

Misiolek, W.S. and D.G. Perdue, 1987. "The Portfolio Approach to State and Local Tax Structure," National Tax Journal 40(1), 111-114.

Morgan, W., J. Mutti, and D. Rickman, 1996. "Tax Exporting, Regional Economic Growth, and Welfare," Journal of Urban Economics 39(2), 131-159.

Pesaran, H. and Y. Shin, 1998. "Generalized Impulse Response Analysis in Linear Multivariate Models," Economics Letters 58, 17-29.

Porca, S., 2002. "The Effects of Political Factors, Tax Competition, and Industrial Mix on State Tax Revenue Composition: Theoretical and Empirical Evidence," Doctoral Dissertation, University of Tennessee, Knoxville.

Ramsey, F.P., 1927. "A Contribution to the Theory of Taxation," Economic Journal 37, 47-61.

Rousseau, P.L. and P. Wachtel, 2000. "Equity Markets and Growth: Cross-Country Evidence on Timing and Outcomes, 1980-1995," Journal of Banking and Finance 24, 1933-1957.

Shoven, J.B. and J. Whalley, 1992. "Canada-U.S. Tax Comparisons," National Bureau of Economic Research Project Report. University of Chicago Press: Chicago and London, 1-23.

Stiglitz, J.E. and M.J. Boskin, 1977. "Some Lessons from the New Public Finance," American Economic Review, Papers and Proceedings 77, 295-301.

Suyderhoud, J., 1994. "State-Local Revenue Diversification, Balance, and Fiscal Performance," Public Finance Quarterly 22(2), 168-194.

Villanueva, O.M., 2005. "FX Dynamics, Limited Particpation, and the Forward Bias Anomaly," Financial Review 40(1), 67-93.

Wagner, R.E., 1976. "Revenue Structure, Fiscal Illusion, and Budgetary Choice," Public Choice 25(25), 45-61.

Wang, P. and P. Dunne, 2003. "Real Exchange Rate Fluctuations in East Asia: Generalized Impulse-Response Analysis," Asian Economic Journal 17(2), 185-203. 
Warskett, G., S.L Winer, and W. Hettich, 1998. "The Complexity of Tax Structure in Competitive Political Systems," International Tax and Public Finance 5(2), 123-151.

White F.C., 1983. "Trade-Off in Growth and Stability in State Taxes," National Tax Journal 36(1), 103-114. 